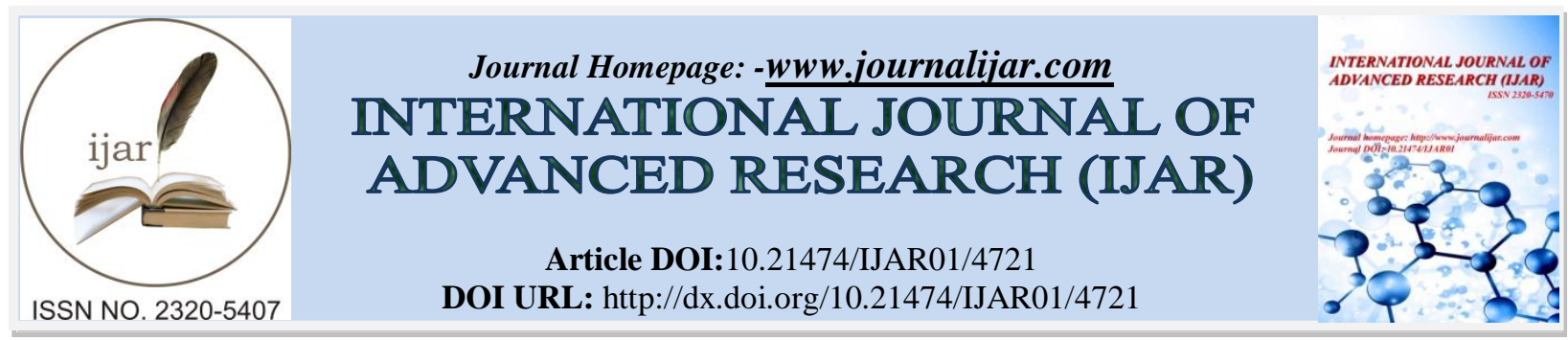

RESEARCH ARTICLE

\title{
CHAETOTAXY, BIOMETRY AND BIOLOGY OF A HOLOTYPE: CUNEXA TERMINALAE SP. NOV. COLLECTED FROM TERMINALIA ARJUNA IN SUNDARBANS BIOSPHERE RESERVE.
}

\section{Dr. Sanjib Ghoshal.}

Assistant Professor, Postgraduate Department of Zoology, Bangabasi College, Kol-700009.

\section{Manuscript Info}

Manuscript History

Received: 4 May 2017

Final Accepted: 6 June 2017

Published: July 2017

Key words:-

Chaetotaxy, Biomemtry, Biology, predatory mite.

\section{Abstract}

One new species of genus Cunexa was reported by the author from Sajnekhali Tiger Reserve, within Sundarban Biosphere Reserve, 24Paraganas (South). The species was collected from Terminalia arjuna. The species was belonging to Cunaxidae family. The species is close to Cunaxa potchensis Den Heyer (1979) but differs in having setae $\mathrm{D}_{4}$ and $\mathrm{D}_{5}$ smooth and not stipulate as well as in Chaetotaxy of palp. It also differs from Cunaxa setirostris (Hermann) in lacking long seta on palptarsus and lacking strong spine like seta on palp genu. Males are not reported by the author.

Biology of the species was studied in the laboratory condition on the leaves of Terminalia arjuna. As because the males are not found during the present study, parthenogenetic life cycle was studied in the laboratory condition. It was found that the mean incubation period was $3.45 \pm 0.72(\mathrm{n}=10)$ days. The percentage of hatching was $94.45 \pm 0.76$ $(\mathrm{n}=10)$. The mean duration of Protonymphal stage was $2.46 \pm 0.92$ days $(n=10)$. The mean duration of deutonymphal stage was $3.06 \pm$ 0.27 days $(n=10)$. The mean egg to adult period was $7.76 \pm 0.26$ $(\mathrm{n}=10)$ days. It was also observed that the percentage of mortality was $31.62 \pm 0.42(n=10)$. The mean pre-oviposition period was $3.06 \pm 0.35$ days $(\mathrm{n}=10)$. The fecundity in the present study was found to be $17.76 \pm$ 0.54 eggs. The mean postoviposition period in the present study was $8.22 \pm 0.62(\mathrm{n}=10)$ days. The average adult longevity in female was found to be $14.39 \pm 0.76$ days $(n=10)$. The Male : Female ratio was found to be $1: 1.44$.

Copy Right, IJAR, 2017,. All rights reserved.

\section{Introduction:-}

Sundarbans Biosphere Reserve (SBR) is very rich with at least 36 species of mangroves vegetations of the 55 species of mangrove plants that are known to occur in the world. Unfortunately, the knowledge about the plant mite faunal wealth of this region is very inadequately explored as appeared from the fact that only 6 species are so far known occurring on mangrove vegetation of that region (Gupta, 1992). So it was through desirable to explore mangrove vegetation regarding mite population. During the present study the author found a new species and an extensive study of the new species is given in this paper. 


\section{Methodology:-}

Collection is made during field visits. The mites were collected from Terminalia arjuna. The leaves are examined by plucking at random 40-50 leaves from each plant and examining those under 20X lens in the field. The mites were collected with fine sable hair brush moistened with $70 \%$ ethyl alcohol. Collected samples were kept in small glass vials $(3 \mathrm{~cm} \times 1 \mathrm{~cm})$ in $70 \%$ ethyl alcohol and were tightly closed with a screw cap. In addition, plant samples were brought to the laboratory in air tight polythene bags and those were examined under a stereo-binocular microscope for collection of specimens. The mites were picked up with a sable hair brush moistened with $70 \%$ ethyl alcohol.

The collected samples were preserved in $70 \%$ ethyl alcohol contained in glass vials of $5 \mathrm{~cm} \times 2 \mathrm{~cm}$ size. Later, those vials were stored in bigger glass jar filled with ethyl alcohol to avoid any evaporation of alcohol and thus prevent drying of specimens.

For temporary mounting the contents of vials were emptied into a cavity block. The specimens were picked up under stereobinocular microscope by a fine brush and were put in a drop of lactic acid on a glass slide and then the same was covered with a broken piece of cover glass to minimize the weight of the glass on the specimens. It was then gently heated on an electric lamp (40W) for a few seconds until lactic acid fumes started emerging. Later, a little time was allowed to elapse so that the lactic acid fumes to subside. Thereafter, specimens were examined under a research microscope (magnification $10 \times 40$ to $10 \times 100$ ).

After the identifications were over, the specimens were removed with a sable hair brush under a stereobinocular microscope and were either mounted permanently on another slide or were transferred back in vials containing ethyl alcohol for storage. For permanent mounting, the PVA medium as suggested by Heinz ( Evans\& Till, 1979) was used. To avoid drying of mounted slides and subsequent shrinkage of the specimens, the slides were sealed with good quality nail polish and stored in slide cabinets.

Illustration of mite specimens along with body parts of taxonomic importance, whenever required, was prepared using a prism type Camera Lucida. The measurements of different body parts were taken using a previously calibrated ocular micrometer.

For the study of life cycle, leaf - disc technique was followed. The excised leaf of Terminalia arjuna was kept on wet cotton swab in a petri dish of $5 \mathrm{~cm}$ diameter.

The cotton swab was always kept supersaturated with water to prevent escape of mites. The excised leaf of Terminalia arjuna was kept on cotton swab ventral surface upward. Ten females collected from field were released on the leaves kept on the wet cotton swab and the females were allowed to lay eggs. After 24 hours the eggs were counted, marked and the females were removed leaving only the eggs. The eggs were kept as such till they hatched into larvae. After hatching, each larva was transferred on individual petridish and for each stage at least 10 replications were maintained enabling the data to analyze statistically. Observations were recorded at 12 hourly interval till they attained adulthood.

Whenever, the eggs hatched, the larvae were removed and kept on a separate excised leaf on petridish and all those were maintained individually till attaining adulthood. All the petridishes were kept in BOD incubators where the desired temperature i.e., $30^{\circ} \mathrm{C}$ was maintained. During the study period the drying or decaying excised leaves were replaced with fresh ones and the mites were transferred carefully on fresh excised leaves.

For studying sex ratio, some females were released on excised leaves kept on wet cotton swabs in petridishes and were allowed to lay eggs. After laying of sufficient eggs, all the females were removed on the following day and the total number of eggs obtained were counted. The eggs hatched into larvae and those gradually developed into adults passing through different stages. Thereafter, among the total adults obtained, the total number of females and males were counted and ratio of males and females were computed on the basis of total number of eggs with which the experiment was started.

The duration of different stages like incubation, protonymphal, deutonymphal, adult, egg to adult, preoviposition, oviposition, postoviposition, fecundity and longevity were recorded. The data were subjected to statistical analysis. 


\section{Results:-}

Female:-

Body measures from posterior tip of the body upto anterior tip of gnathosoma was $525 \mu$ long and $262.5 \mu$ width. Hypostome conical with four pairs of setae ventrally. Propodosomal shield with 4 pairs of setae including two pairs of sensoty setae. Anterior sensory seta $150 \mu$ long.The posterior sensoty setae $206.25 \mu$ long.Seta P1, P2, very small.Hysterosomal shield absent, setae D1-D5 and L1 present on hysterosoma, the length of which vary from 10-15 $\mu$. Palp five segmented.

Palp chaetotaxy: Trochentor-nil, basifemur -1 lateral, 1 ventral, telofemur- 1 dorsal, genu-1 lateral. One strong spine like ventral seta and one long dorsal seta, which riches almost upto middle of tibiotarsus.Tibiotarsus-3 lateral, 2 dorsal, 1 ventral seta.Spur or spine like seta absent.Chelicera broad at vase gradually tapering distally with cheleceral digit.

Leg Chaetotaxy: I-IV: trochentor-1,1,2,1; basifemur- 2,2,1,1.: Telofemer- 2,2,4,3. Genu-2+1 solenidion, 3,2; Tibia$3,1,3,2+1$ solenidion; Tarsus- $8+1$, Solenidion, 2, 9+1 solenidion; ventrally three pairs of anal setae and three pairs paragenital setae present.

Male: Unknown.

The species is close to Cunaxa potchensis Den Heyer (1979) but differs in having setae $\mathrm{D}_{4}$ and $\mathrm{D}_{5}$ smooth and not stipulate as well as in Chaetotaxy of palp. It also differs from Cunaxa setirostris( Hermann) in lacking long seta on palptarsus and lacking strong spine like seta on palp genu.

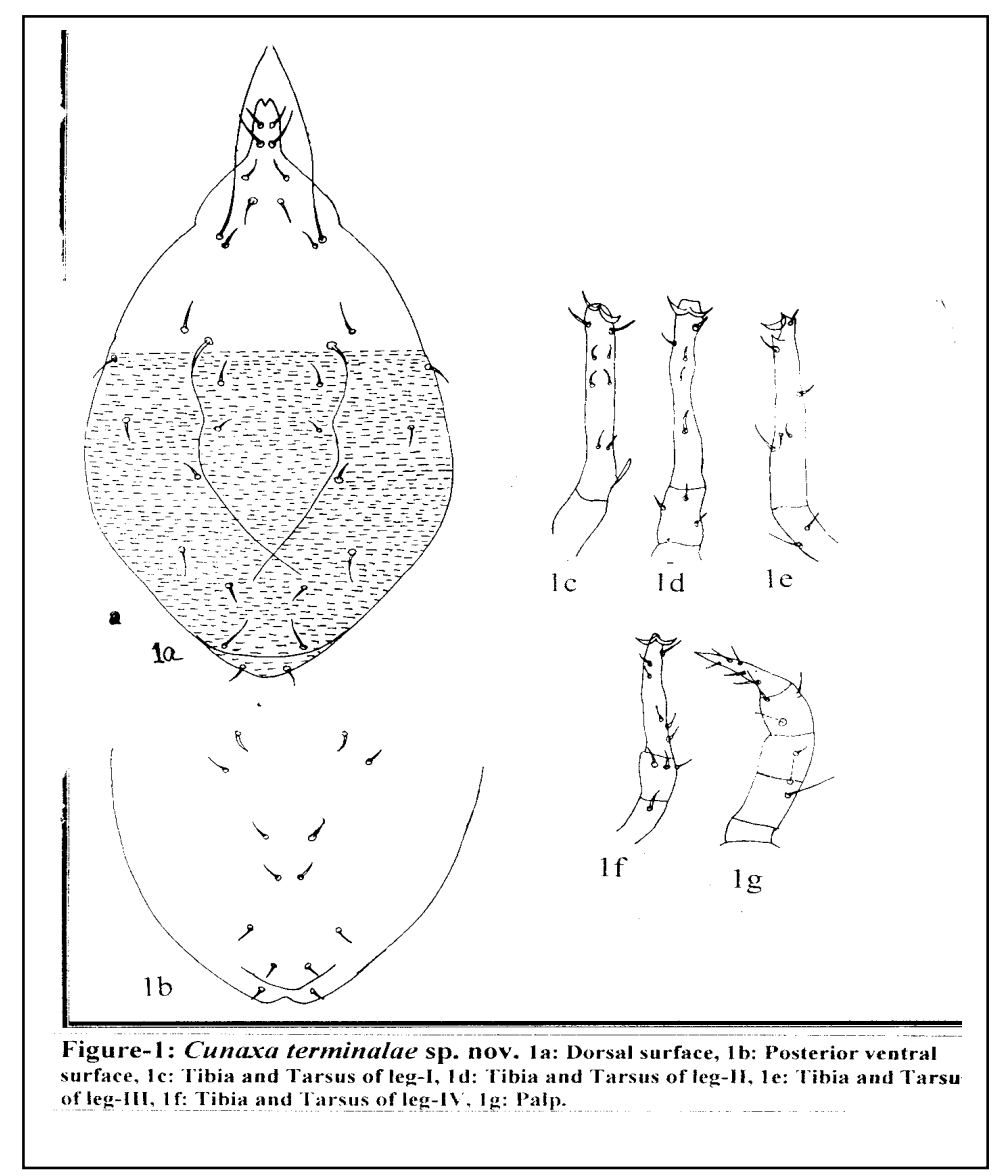

The eggs were elliptical (50-70 micron in length), transparent and laid in a scattered manner on the under surface of the leaves. The minimum incubation period was 2.0 days and maximum was 3.0 days with the mean of $3.45 \pm 0.72$ $(\mathrm{n}=10)$ days. The percentage of hatching was $95.45 \pm 0.76(\mathrm{n}=10)$. The incubation periods as were reported for other Phytoseiid mite from India were 1.92 days for A. tetranychivorus (Jagadish\&Nageschandra, 1979), 44 hours 42 minutes for A. longispinasus (Mallik and ChannaBasavanna, 1983), $50.38 \pm 5.01$ hours for A.. ovalis (Borah 
\&Rai, 1989) feeding on castor pollen, $50.04 \pm 0.91$ hours for Amblyseius concordis (Jagadish, et al. 1990), 32.52 hours for Amblyseius delhiensis (Nageshchandraet al., 1998). The period was reported to be $2.30 \pm 0.14$ days in case of Amblyseius alstoniae feeding upon Eotetranychus hicoriae on guava leaves (Gupta et al. 2003). The period was $1.72 \pm 0.02$ days in case of Amblyseius multidebntatus feeding upon Eotetranychus fremonti on Avicennia alba leaves (Ghoshal et at., 2004). Hence, the incubation period as observed in the present case was within the reported duration for this stage.

The mean duration of Protonymphal stage was $2.46 \pm 0.92$ days $(n=10)$. It was more active than the larva and had four pairs of legs. The duration of this stage in case of other phytoseiid species was 22.2 hours in $A$. channabasavannai (Daniel, 1981), 1.06 days in A. tetranychivorous (Jagadish\& Nageschandra,1982), 20 hours 53 minutes for A. longispinosus (Mallik and ChannaBasavanna,1983). The period was reported to be $2.30 \pm 0.15$ days in case of Amblyseius alstoniae feeding upon Eotetranychus hicoriae on guava leaves. (Gupta et al. 2003). The period was $1.60 \pm 0.25$ days in case of Amblyseius multidebntatus feeding upon Eotetranychus fremonti on Avicennia alba leaves (Ghoshal et at., 2004). Hence, the period as observed in the present case was within the reported duration for this stage.

The mean duration of deutonymphal stage was $3.06 \pm 0.27$ days $(n=10)$. The duration of this stage in case of other phytoseiid species was 23.8 hours in A. channabasavannai (Daniel, 1981), 0.92 days in A. tetranychivorous (Jagadish \& Nageschandra,1982). 21 hours 51 minutes in A. longispinosus (Mallik and ChannaBasavanna,1983). The period was reported to be $3.25 \pm 0.45$ days in case of Amblyseius alstoniae feeding upon Eotetranychus hicoriae on guava leaves. (Gupta et al. 2003). The period was $2.30 \pm 0.36$ days in case of Amblyseius multidebntatus feeding upon Eotetranychus fremonti on Avicennia alba leaves (Ghoshal et at., 2004). Hence, the period as observed in the present case was within the reported duration for this stage.

The mean egg to adult period was $7.76 \pm 0.26(\mathrm{n}=10)$ days. It was also observed that the percentage of mortality was $32.62 \pm 0.42(\mathrm{n}=10)$. In case of other Phytoseiid species the period (egg-adult) were $140 \pm 7.51$ hours in $A$. tetranychivorous (Puttaswamy, 1978), 85.10 hours in A. channabasavannai (Daniel, 1981), $5.8 \pm 0.40$ days at $30^{\circ} \mathrm{C}($ Sharma \&Sadana, 1985). Therefore the total life cycle in the present case was $8.36 \pm 0.26(\mathrm{n}=30)$ days and this tallies with those observed by other workers excepting A. longispinosus which took longer period (Nangia et al., 1990). The period was reported to be $9.50 \pm 0.39$ days and percentage of mortality was 22.00 in case of Amblyseius alstoniae feeding upon Eotetranychus hicoriae on guava leaves. (Gupta et al. 2003). The period was $7.35 \pm 0.15$ days and percentage of mortality was 28.00 in case of Amblyseius multidebntatus feeding upon Eotetranychus fremonti on Avicennia alba leaves (Ghoshalet at., 2004).

The mean pre-oviposition period was $8.22 \pm 0.62$ days $(n=10)$. However, this period is nearer to be duration observed where it was reported to be $4.50 \pm 1.93$ hours in A. channabasavannai (Daniel, 1981), 3.63 days in case of A .tetranychivorous (Jagadish\&Nageschandra 1982). The mean oviposition period was found to be very brief $4.35 \pm$ 0.75 days) ( $\mathrm{n}=10)$ excepting Nageshchandra et al., (1998) who reported this period to be 2.46 days in A. delhiensis while in all other cases the oviposition period was much longer for example $15.7 \pm 1.71$ days in $A$. channabasavannai (Daniel, 1981). The mean postoviposition period in the present study was $7.44 \pm 0.48$ ( $\mathrm{n}=10$ ) days which appeared to be much longer as compared to the duration observed by other workers, viz., 5.12 days in $A$ tetranychivorous (Jagadish\& Nageschandra,1982) and $10.00 \pm 1.76$ days in Phytoseiulus persimilis (Krishnamoorthy 1989). The period was reported to be $3.72 \pm 0.15$ days in case of Amblyseiusalstoniae feeding upon Eotetranychus hicoriae on guava leaves. (Gupta et al. 2003). The period was $1.43 \pm 0.49$ days in case of Amblyseius multidebntatus feeding upon Eotetranychus fremonti on Avicennia alba leaves (Ghoshal et at., 2004). Hence, the period as observed in the present case was within the reported duration for this stage.

The average adult longevity in female was found to be $14.39 \pm 0.76$ days $(n=10)$ which came closer to observations made by other workers like $18.6 \pm 1.49$ days in female of A. finlandicus (Sharma \&Sadana, 1985). The average fecundity was rather poor. The value was $17.06 \pm 0.54$ eggs $(n=10)$. In other Phytoseiid species this was reasonably higher as 27.3 in A. channabasavannai (Daniel, 1981) and 26.8 eggs in A. tetranychivorous (Jagadish\& Nageschandra,1982). The Male : Female ratio was found to be $1: 1.44$. Almost similar observations were reported to be 1:3.30 in A. finlandicus (Sharma\&Sadana 1985) and 1: 4.87 in Phytoseiuus persimilis (Krishnamoorthy, 1989). So, the sex ratio was female-biased as the observations made by the other workers. The adult longevity was reported to be $17.25 \pm 0.39$ days and fecundity was $11.87 \pm 0.67$ in case of Amblyseius alstoniae feeding upon Eotetranychus hicoriae on guava leaves. (Gupta et al. 2003). The adult longivity was $12.01 \pm 0.71$ days and fecundity was $18.01 \pm$ 
0.56 in case of Amblyseius multidebntatus feeding upon Eotetranychus fremonti on Avicennia alba leaves (Ghoshal et at., 2004). Hence, the period as observed in the present case was within the reported duration for this stage.

Table-1:-Duration of different life stages of Cunexa terminalae feeding upon Terminalia arjuna leaves Under Laboratory Condition At Controlled Temperature $\left(30^{0} \pm 1^{0} \mathrm{C}\right)(\mathrm{n}=10)$

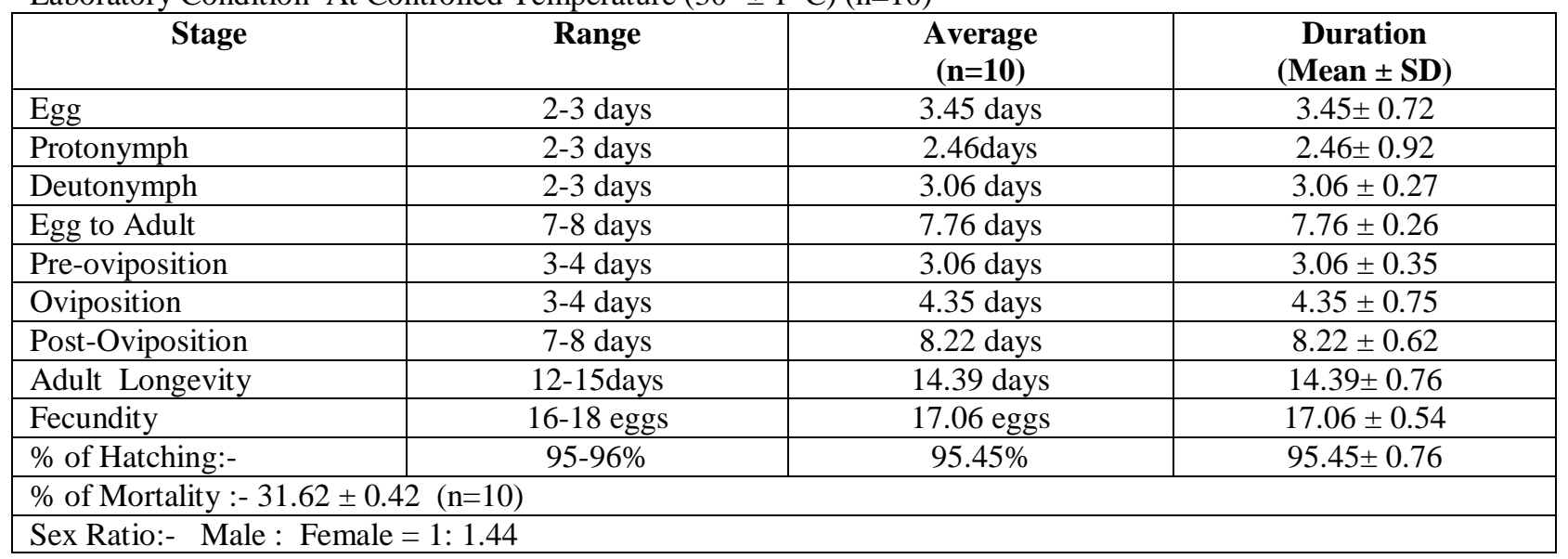

\section{References:-}

1. Borah, D.C.\&Rai, P.S. 1989. Potentiality of Amblyseiusovalis (Acari: Phytoseiidae) as the control agent on Bemesiatabaci (Homoptera: Aleyrodidae) In: Progress in Acarology, 2: 375-379.

2. Canestrini, G. \& R. 1881. Atti. Ist. Veneto, (5) 7: 1083.

3. Daniel, M. 1981, Bionomics of predaceous mite Amblyseiuschannabasavanni(Acari: Phytoseiidae), predaceous on the palm mite. In: Contribution to Acarology in India, pp. 167-173.

4. Evans, G.O. \& Till, W.M. 1979. Mesostigmatic mites of Britain and Ireland (Chelicerata: Acari: Parasitiformes). An introduction to their external morphology and classification. Trans. Zool. Soc. Lond., 35: 139-270.

5. Ghoshal S., Gupta, S.K. and choudhury, A. Life cycle of Amblyseiusmultidentatus at room temperature feeding upon Eotetranychusfremonti on Avicennia alba blume. Rec. Zool. Surv. India: 102 (Part 3-4): 47-52, 2004.

6. Gupta, S.K. 1992. Arachnida: Plant Mites ( Acari) with descriptions of nineteen new species. State Fauna Ser 3 , Fauna of West Bengal, Part3, pp. 61-211.

7. Gupta, S.K., Ghoshal, S., Choudhury, A. Life cycle of Amblyseiusalstoniae Gupta, at room temperature feeding upon Eotetranychushicoriae McGregor on Guava ( Psidiumguajava). Rec. Zool. Surv. India: 101 (part 1-2): 9399, 2003.

8. Jagadish, P.S., Channabasavanna, G.P. \&Nageschandra, B.K. 1990. Biology of predatory mite Euseiusconcordis (Chant) (Acari: Phytoseiidae) and effective predator of Tetranychusneocaledonicus (Andre). (Acari: Tetranychidae). Abst. IV Nat. Symp. Acarology., p.14.

9. Jagadish, P.S. \&Nageschandra, B.K., 1979, Biology of Tryphodromipstetranychivorous (Acari: Phytoseiidae) red palm mite Raoiellaindica (Acari: Tenuipalpidae). Abst. I All India, Symp. Acarology, Bangalore. p. 49.

10. Jagadish, P.S. \&Nageschandra, B.K., 1982. Biology of Typhlodromipstetranychiborus (Acari: Phytoseiidae) on red. Palm maiteRaoiellaindia (Acari: Tenuipalpidae). Abst. I All India Symp. Acar., p. 49.

11. Krishnamoorthy, A. 1989. Development of Phytoseiuluspersimilis (Acari: Phytoseiidae) on the carmine spider mites Tetranychuscinnabarinus (Acari: Tetranychidae) at two temperature regimes. In: Progress in Acarology, 2: 369-374.

12. Mallik, B. \&ChannaBasavanna, G.P. 1983. Life history and life tables of Tetranychusludeni and its predator Amblyseiuslongispinosus( Acari: Tetranychidae, Phytoseiidae), Indian J. Acar., 8 (1): 1-13.

13. Nageschandra, B.K., Jagadish, P.S., Nangia, N. \&ChannaBasavanna, G.P. 1998. An appraisal of potentialities of Amblyseiusdelhiensis Narayanan \&Kaur (Acari: Phytoseiidae) in suppressing population of guava mite Eotetranychushicoriae (Acari: Tetranychidae)Abst. X Internat. Congress Acarology. p. 149.

14. Nangia, N., ChannaBasavana, G.P. \&Jagadish, P.S., 1990. Red spider mite and their predators on papya. A secondary food plant on eri silk worm. Acarol. Newlt. 17-18: 21-24. 